\title{
Mood and Luxury Perception: A Tale of Two Genders: An Abstract
}

\author{
Michaela Hoogerhyde and Mazen Jaber
}

\begin{abstract}
The effects of mood and gender on consumption and decision-making are well documented in consumer behavior research. While a lot of research focuses on the effect of mood, gender, or their interaction on purchase likelihood, very few studies, if any, explore those effects on luxury perception. This paper tackles that very question. We begin by reviewing literature on gender, mood, luxury perception, and materialism, among other variables, and then build a conceptual model that explores interaction between mood and gender on luxury perception.

Our results show that males rated the products as more luxurious when they were in a negative mood than when they were in a positive mood. In addition, males in a negative mood had a significantly higher luxury perception than females in a negative mood. Alternatively, females rated the products in the experiment as more luxurious when they were in a positive mood than when they were put into a negative mood state. Females also rated the products as more luxurious than males when both genders' moods were positive. Further supporting previous research, males also exhibited a higher product attitude than females did when participants were in a negative mood. Males also rated a higher product attitude evaluation when they were in a negative mood than in a positive mood. The results also confirm that the high-priced luxury item was rated as more luxurious than the lower-priced product when participants were in a positive mood. This research contributes in the luxury perception literature by recognizing the gender and mood effects on perception and product attractiveness.
\end{abstract}

M. Hoogerhyde $\cdot$ M. Jaber $(\square)$

Saginaw Valley State University, University Center, MI, USA

e-mail: mhoogerh@svsu.edu; mjaber@svsu.edu 